\title{
LONG-TERM CLINICAL AND RADIOLOGICAL RESULTS OF THE LORD TOTAL HIP PROSTHESIS
}

\author{
A PROSPECTIVE STUDY
}

\author{
HENRIK MALCHAU, PETER HERBERTS, YU XING WANG, \\ JOHAN KÄRRHOLM, BERTIL ROMANUS \\ From Sahlgrenska and East University Hospitals, Gothenburg, Sweden
}

W Je enrolled 98 patients (107 hips) with a mean age of 47 years (SD 8.6) into a prospective study of the Madreporic Lord THR; 34 hips had primary and 73 secondary osteoarthritis.

After ten years, the survival rate using revision as the endpoint for failure was $70 \%( \pm 9)$ for the cup and $98 \%( \pm 0.3)$ for the stem. The combined clinical and radiological survival rates were $46 \%( \pm 11)$ and $81 \%$ $( \pm 10)$, respectively. Osteoporosis due to stress-shielding was observed in the proximal femur. Hips with radiologically dense bone postoperatively showed the most pronounced bone loss.

We recommend continued radiological follow-up of patients with this type of implant to allow revision to be performed before there is severe bony destruction of the pelvis.

J Bone Joint Surg [Br] 1996;78-B:884-91.

Received 4 April 1996; Accepted after revision 22 April 1996

In the 1970s Lord developed an uncemented cobalt-chromium implant with a fully porous (Madreporic) coated stem and a threaded cup. Initial stem fixation depended on a fit in the tight trochanteric and diaphyseal area. The preliminary results were promising (Lord 1978), but we are not aware of prospective reports of long-term series. Our aim was to assess the efficacy of this implant in a series of young and active patients over a ten-year period.

H. Malchau, MD, PhD, Associate Professor

P. Herberts, MD, PhD, Professor

J. Kärrholm, MD, Associate Professor

Department of Orthopaedics

Y. X. Wang, MD

Department of Diagnostic Radiology

Sahlgrenska University Hospital, S-413 45, Gothenburg, Sweden.

B. Romanus, MD, PhD, Associate Professor

Department of Orthopaedics, East University Hospital, Gothenburg, Sweden.

Correspondence should be sent to Dr H. Malchau.

(C)1996 British Editorial Society of Bone and Joint Surgery 0301-620X/96/61263\$2.00

\section{PATIENTS AND METHODS}

Between September 1979 and November 1986 we enrolled 98 patients in the study, all of whom gave their informed consent. Nine had bilateral operations, giving a total of 107 arthroplasties. Patients were excluded if they had active inflammatory disease, severe osteoporosis, corticosteroid treatment for more than three months, a previous replacement of the same hip, or grossly deficient femoral or acetabular bone stock.

Of the 107 hips, 34 showed primary osteoarthritis, and 33 had arthritis secondary to childhood diseases. Thirteen had old fractures of the acetabulum or femoral neck, 13 had idiopathic avascular necrosis, 7 showed inflammatory arthritis, and 7 miscellaneous disorders. Fifty-nine patients (60\%) had unilateral hip disease only (Charnley group A), 28 had bilateral hip disease (group B) and 11 had multiple joint involvement (group C) (Charnley 1979).

There were 40 men and 58 women with a mean age of 47 years (SD 8.6; 25 to 67) and a mean weight of $70 \mathrm{~kg}$ (SD 12). All the patients were operated on at the two University hospitals in Gothenburg, most of them by one of the two senior authors (PH, BR). After 1984, other uncemented implants were also used and therefore the series is not consecutive for the last two years.

Clinical data and follow-up. For clinical evaluation we used a standard proforma recording age, gender, weight, diagnosis, social and working status, previous operation(s), Charnley class, subsets of the Harris hip score, implant size, peroperative assessment of bone quality and peroperative fracture. The Harris hip score and subsets of this score were used for outcome measurement (Harris 1969).

We performed clinical and radiological examinations before and after the operation and at 1, 3, 5, 7, 10 and 13 years. For up-to-date information about revisions, especially for patients who had only one component revised or had been revised after the latest follow-up, we used the National Register of THA in Sweden (Malchau, Herberts and Ahnfelt 1993).

Patients were withdrawn from the study (Table I) when the cup $(n=39)$, the stem $(n=1)$ or both components $(n=1)$ were revised or extracted. Seven patients (7 hips) died 3 to 14 years after the operation and one patient emigrated and could not be contacted. The postoperative 
Table I. Number of hips evaluated at different follow-up intervals. Hips revised and patients deceased or lost to follow-up are listed at their last follow-up before being withdrawn

\begin{tabular}{|c|c|c|c|c|c|c|c|}
\hline \multirow[b]{2}{*}{$\begin{array}{l}\text { Follow-up } \\
(\mathrm{yr})\end{array}$} & \multicolumn{2}{|c|}{ Clinical examination } & \multicolumn{2}{|c|}{ Radiological examination } & \multicolumn{2}{|c|}{ Withdrawn hips } & \multirow[b]{2}{*}{$\begin{array}{l}\text { Lost to } \\
\text { follow-up }\end{array}$} \\
\hline & Yes & No & Yes & No & $\begin{array}{l}\text { Revision } \\
\text { or extraction }\end{array}$ & Deceased & \\
\hline 1 & 101 & 5 & 86 & 21 & & 1 & \\
\hline 3 & 91 & 12 & 86 & 17 & 2 & & 1 \\
\hline 5 & 87 & 5 & 77 & 12 & 9 & 2 & \\
\hline 7 & 63 & 7 & 70 & 15 & 18 & 4 & \\
\hline 10 & 43 & 6 & 41 & 8 & 12 & & \\
\hline
\end{tabular}

Table II. Details recorded from the digitised radiographs

\begin{tabular}{|c|c|c|}
\hline & View & Definition, grading and reference line or point \\
\hline \multicolumn{3}{|l|}{ Preoperative } \\
\hline Acetabular cysts & AP and lateral & Yes/No \\
\hline Femoral head cysts & $\mathrm{AP}$ and lateral & Yes/No \\
\hline \multicolumn{3}{|l|}{ Immediate postoperative } \\
\hline \multicolumn{3}{|l|}{ Cup } \\
\hline Inclination & AP & Teardrop line (degrees) \\
\hline \multicolumn{3}{|l|}{ Stem } \\
\hline Varus/valgus position & $\mathrm{AP}$ & Femoral $v$ prosthetic longitudinal axis* \\
\hline Fill-fit ratio & AP & Area prosthesis/femoral canal distal to tip of lesser trochanter* \\
\hline Cortical contact ratio & $\mathrm{AP}$ & Length of prosthetic contact/length of prosthesis $\times 2 *$ \\
\hline \multicolumn{3}{|l|}{ Follow-up $v$ Postop } \\
\hline \multicolumn{3}{|l|}{ Cup } \\
\hline Vertical and horizontal cup migration & AP & Teardrop line and teardrop $\dagger$ \\
\hline Sclerotic and lucent lines & $\mathrm{AP}$ and lateral & Length in $3+3$ regions $\ddagger$ \\
\hline Osteolytic area & $\mathrm{AP}$ & Yes/No \\
\hline \multicolumn{3}{|l|}{ Stem } \\
\hline Vertical subsidence & & Tip lesser trochanter - stem shoulder $\dagger$ \\
\hline Sclerotic and lucent lines & AP and lateral§ & Length of sclerotic lines/length of prosthesis $\times 2 *$ \\
\hline Pedestal formation & AP & Length of line in Gruen zone 4 \\
\hline Osteolytic area & AP & Yes/No \\
\hline Change in cortical density & $\mathrm{AP}$ & Difference of bone area in 6 regions $\llbracket$ \\
\hline
\end{tabular}

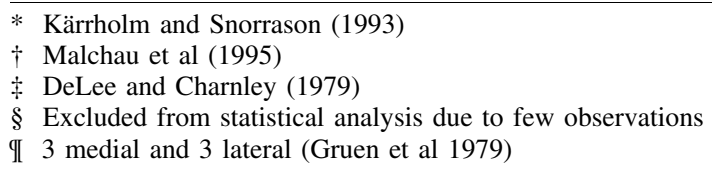

clinical examinations were done by an unbiased observer in more than $75 \%$ of the cases and the remainder by the surgeon. The participating surgeons agreed an overall assessment of the clinical status and the radiological appearance of each case.

Operative procedure. Antibiotic cover and thromboembolic prophylaxis were used in all patients. In 100 hips we used the posterior (Moore 1952) approach and in seven the transgluteal route (Hardinge 1982). Five sizes of cup and eight sizes of stem were available. The two smallest cup sizes were used with a $22 \mathrm{~mm}$ cobalt-chromium femoral head and the larger sizes with a $32 \mathrm{~mm}$ head.

In 15 of the 107 hips (12\%) peroperative complications were recorded. Eight patients had undisplaced spiral femoral fractures due to mismatch between the femoral canal and the design of the stem. Six had undisplaced fractures of the greater trochanter and in one an early reoperation was required to reattach a loose trochanter by cerclage wiring. Radiological analysis. At each review an AP-pelvic view was taken, centred on the symphysis, with AP and lateral femoral views centred on the proximal part of the stem. A total of 2302 radiographs was recorded by video and digitised with a resolution of $1024 \times 1024$ pixels and 256 grayscales, using a frame-grabber card in a personal computer. We developed software for the correction of the planar distortion, and used image analysis software (Research Metrics; OrthoGraphics Inc, Salt Lake City, Utah) to compute distances from landmarks defined by the examiner (Nunn et al 1989; Malchau et al 1995). Only digitally evaluated radiographs were included in the analysis shown in Table II. Previous determinations of the accuracy of our radiological measurements of cup migration and stem subsidence (Malchau et al 1995) enabled us to regard the implant as having migrated if the distance exceeded $5 \mathrm{~mm}$.

We used a new method for the semiquantitative evaluation of change in mineral content of the proximal femoral bone. We traced the outline of visible cortical bone in the seven regions of Gruen, McNeice and Amstutz (1979) on to the digitised radiograph. The areas were measured on the 
Table III. Mean (SD, range) Harris hip score for pain and percentage at score levels of 0 to $20,30,40$ and 44

\begin{tabular}{lllllll}
\hline \multirow{2}{*}{$\begin{array}{l}\text { Follow-up } \\
\text { (yr) }\end{array}$} & Number & \multicolumn{3}{l}{ Score } \\
\cline { 2 - 7 } & & $\mathbf{0}$ to $\mathbf{2 0}$ & $\mathbf{3 0}$ & $\mathbf{4 0}$ & $\mathbf{4 4}$ \\
\hline Preoperatively & 107 & $5.2+7.2(0$ to 30$)$ & 99.0 & 1.0 & & \\
1 & 101 & $40+6.2(10$ to 44$)$ & 2.2 & 6.9 & 16.8 & 74.3 \\
3 & 91 & $42+4.9(29$ to 44$)$ & 2.4 & 5.9 & 17.6 & 74.1 \\
5 & 87 & $42+5.1(20$ to 44$)$ & 2.1 & 8.5 & 20.2 & 69.1 \\
7 & 63 & $41+5.5(20$ to 44$)$ & 3.5 & 7.1 & 31.8 & 57.6 \\
10 & 43 & $41+6.7(10$ to 44$)$ & 3.8 & 3.8 & 30.2 & 62.3 \\
\hline
\end{tabular}

postoperative and the follow-up AP radiographs, compensating for different exposures by adjustment of the brightness on the monitor to the level at which the bone trabeculae in the centre of the tuber ischii precisely faded away. The intra- and interobserver errors for the method were assessed on 15 radiographs analysed twice with an interval of one month by three observers (HM, YXW and JK).

We defined focal or linear osteolytic areas as rounded or longitudinal areas showing decreased bone density, localising them by the regions of DeLee and Charnley (1976) on the acetabular side and Gruen et al (1979) on the femoral side.

Definition of failure. We defined clinical failure as revision with exchange or extraction of one or both prosthetic components or exchange of a polyethylene liner. Radiological failure of the cup was defined as migration exceeding $5 \mathrm{~mm}$ in any direction, and radiological failure of the stem as subsidence of over $5 \mathrm{~mm}$. Focal osteolyses were not classified as radiological failures because of their small size and location.

Statistical methods. We used survivorship analysis according to Kaplan and Meier (1958). The proportion of surviving hips $( \pm 1.96$ SEM) was calculated and indicated on the survival curves. The statistical methods used are indicated in the text.

\section{RESULTS}

Clinical results. These are given in Tables III to V and did not change significantly between the first and subsequent follow-ups. Three patients had a transient peroneal nerve palsy, and there were no early deep infections.

The overall assessment of the radiological appearance by the surgeons agreed approximately with the evaluation of the independent observer as regards the stem (Table VI). A time-dependent increase in cup migration was noted by the surgeons, but the proportion of this was smaller than that found by the independent observer.

Revisions. Survival analysis using clinical failure with revision of the cup or stem as the endpoint gave ten-year survival rates of 70\% ( \pm 9$)$ (Fig. 1) and 98\% $( \pm 0.3)$ for the two components, respectively. We found no obvious association between any of the parameters which we evaluated
Table IV. Mean \pm SD (range) Harris hip score for limp and percentage at score levels of 0 to 5 and 8 to 11

\begin{tabular}{llrlr}
\hline \multirow{2}{*}{$\begin{array}{l}\text { Follow-up } \\
\text { (yr) }\end{array}$} & Number & \multicolumn{3}{l}{ Score } \\
\cline { 3 - 5 } Preoperatively & 107 & $1.6 \pm 2.6(0$ to 8$)$ & 95.0 & 5.0 \\
1 & 101 & $9 \pm 2.9(0$ to 11$)$ & 20.2 & 79.8 \\
3 & 91 & $10 \pm 2.7(0$ to 11$)$ & 12.9 & 87.1 \\
5 & 87 & $10 \pm 2.6(0$ to 11$)$ & 11.7 & 88.3 \\
7 & 63 & $9 \pm 2.6(0$ to 11$)$ & 11.7 & 88.3 \\
10 & 43 & $9 \pm 2.9(0$ to 11$)$ & 11.4 & 88.6 \\
\hline
\end{tabular}

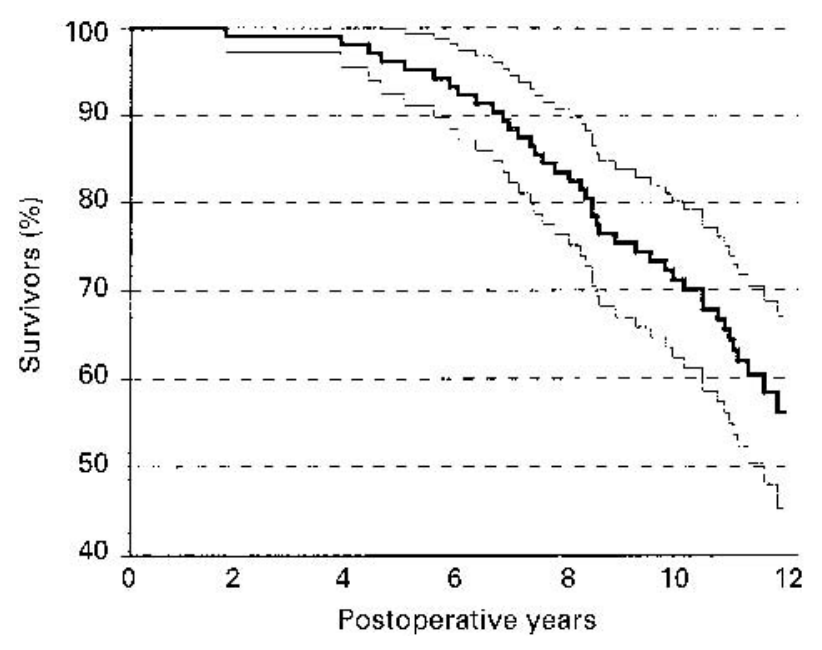

Fig. 1

Survival rate using failure with cup revision as the endpoint. The $95 \%$ confidence limits are shown.

and revision of the cup (Cox proportional hazard regression analysis). Forty cups and two stems (40 hips) were exchanged or revised, but there were too few stem revisions for statistical analysis. The main reasons for revision were aseptic loosening (36 hips), and localised acetabular or femoral osteolysis (3 hips). One patient required a twostage revision after ten years for late deep infection with cup loosening. None of the stems in hips with revised cups has so far been revised.

Radiological results. At one year 7 of 86 cups $(8 \%)$ had migrated more than $5 \mathrm{~mm}$ in the vertical or horizontal direction (Fig. 2). After ten years, 23 of the 41 remaining cups $(56 \%)$ had migrated (Table VII). During the first 


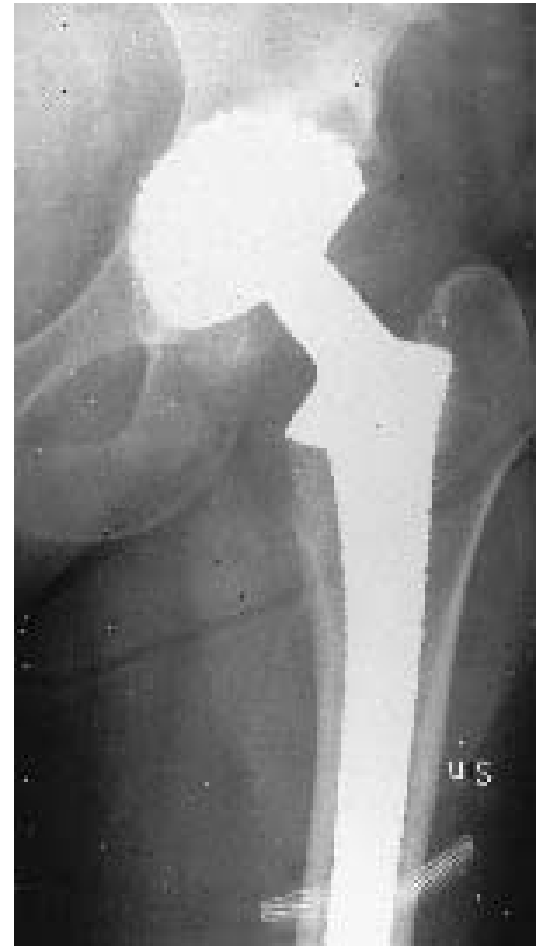

Fig. 2a

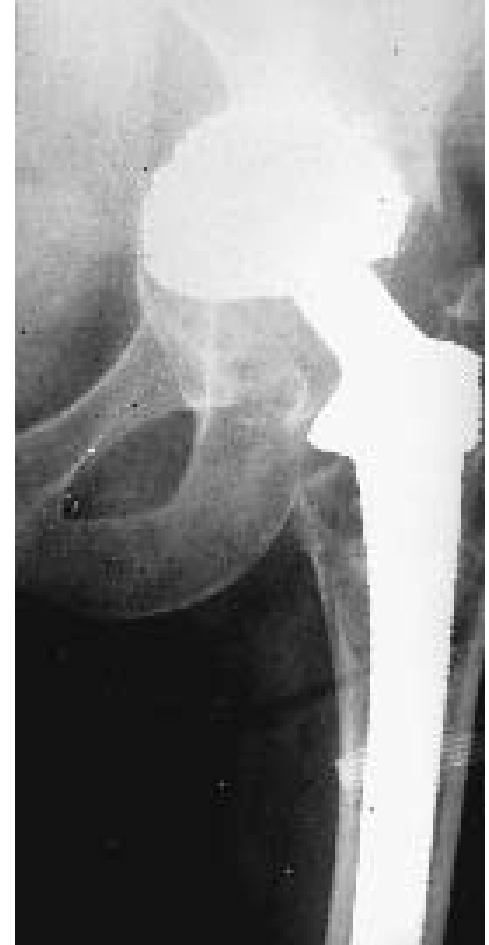

Fig. $2 b$

Postoperative (a) and ten-year radiographs (b) showing migration into the pelvis in a 48-year-old woman with primary osteoarthritis.

postoperative year 6 of 80 stems $(7.5 \%)$ had subsided $5 \mathrm{~mm}$ or more and at the ten-year examination 5 of 32 stems (16\%) had subsided (Table VII, Fig. 3).

A total of 17 stems migrated more than $5 \mathrm{~mm}$. In six this migration was first noted at the one-year follow-up, in eight at three years, in two at five years and in one patient the migration was diagnosed as late as ten years after the operation.

On the femoral side six osteolytic granulomas were seen, all in Gruen zones 1 or 7. Minor areas of acetabular osteolysis were seen in three hips, all in zone 3.

Sclerotic lines were frequently seen around the cup, but very few hips developed sclerotic lines or lucencies around the stem (Figs 4 and 5).

In regard to the relative change in area of cortical bone there was no significant difference between the three observers. The intraobserver error ( 2 SD from zero) was $16 \%$ and the interobserver error ( 2 pooled SD) was $28 \%$. The cortical bone area surrounding the femoral stem decreased between

Table V. Sum of hip movement in degrees; mean \pm SD (range)

\begin{tabular}{llc}
\hline $\begin{array}{l}\text { Follow-up } \\
(\mathbf{y r})\end{array}$ & Number & Movement \\
\hline Preoperatively & 107 & $97 \pm 43(0$ to 220$)$ \\
1 & 100 & $192 \pm 39(50$ to 285$)$ \\
3 & 91 & $201 \pm 45(50$ to 325$)$ \\
5 & 87 & $200 \pm 50(50$ to 330$)$ \\
7 & 63 & $191 \pm 46(50$ to 280$)$ \\
10 & 43 & $182 \pm 61(50$ to 310$)$ \\
\hline
\end{tabular}

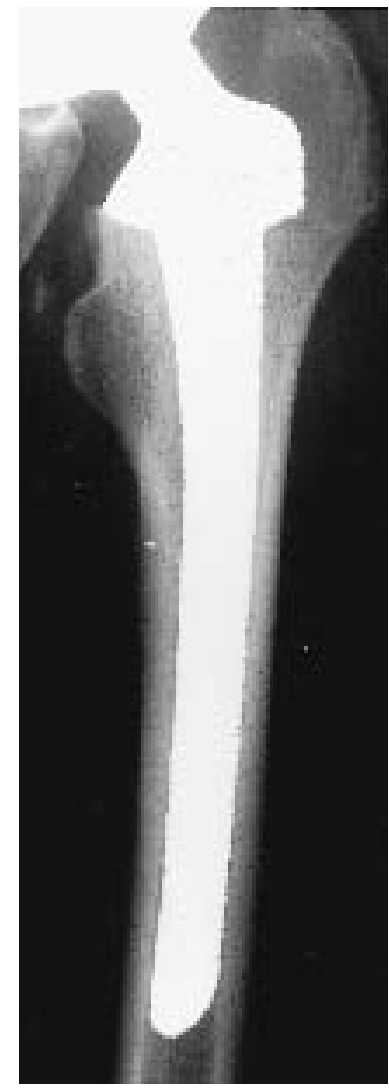

Fig. 3a

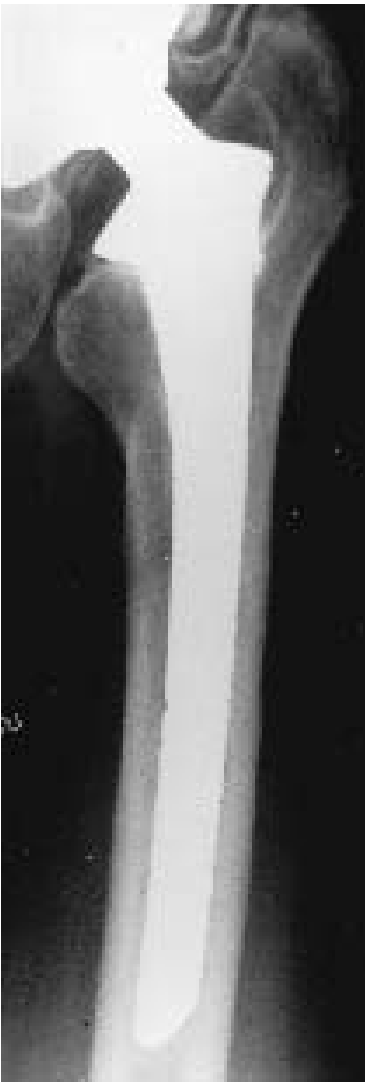

Fig. $3 b$
Postoperative (a) and ten-year follow-up (b) radiographs in a 45-year-old man with primary arthritis. The stem has subsided and the medial cortex has disappeared. 

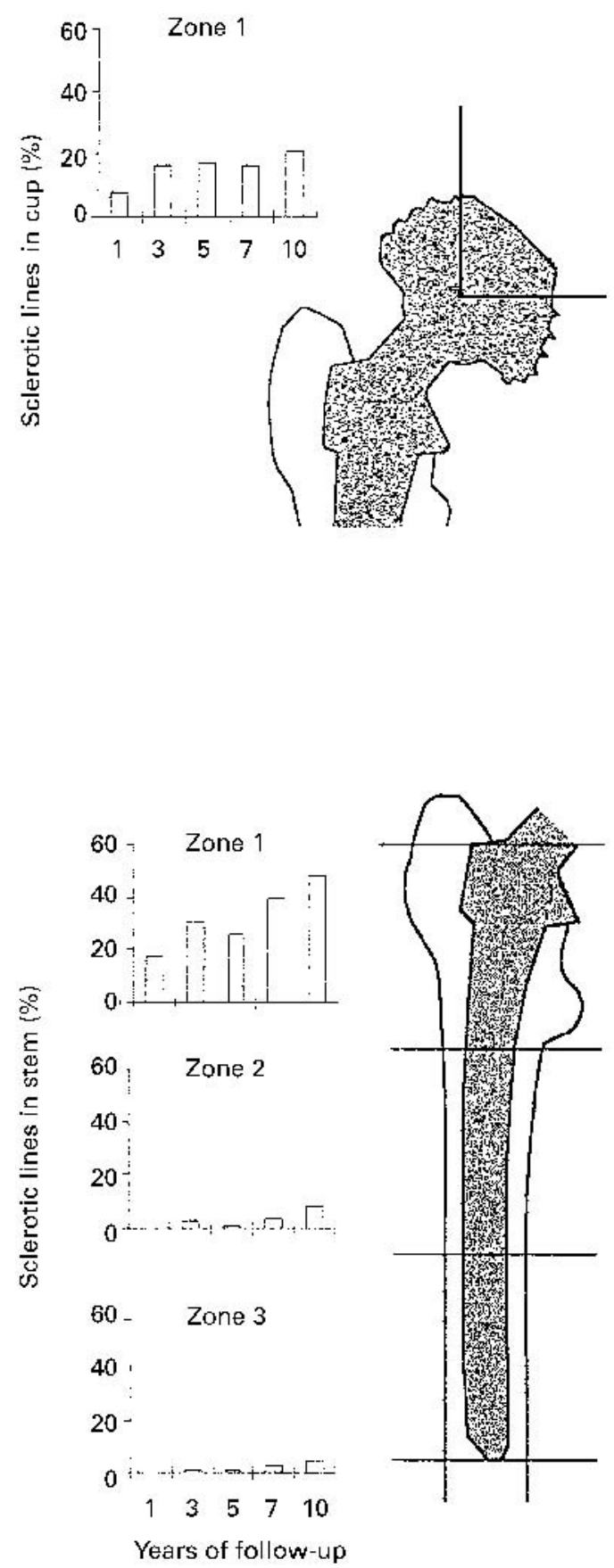

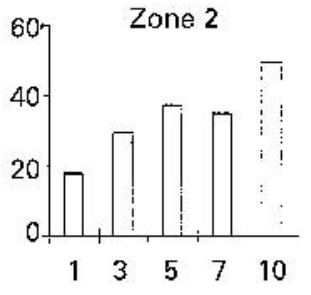

The percentage of sclerotic lines around the cup in zones 1 to 3 (DeLee and Charnley 1982) at the different follow-up times.
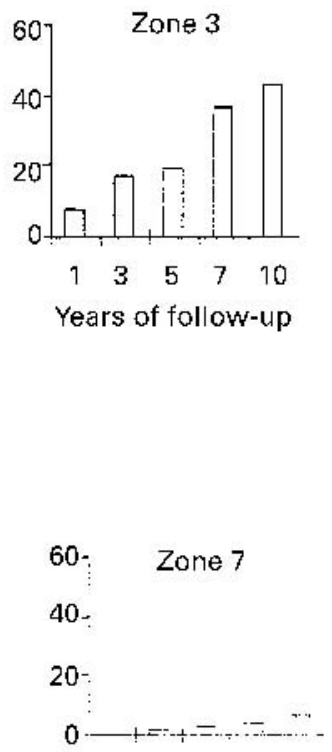

The percentage of sclerotic lines around the stem in zones 1 to 7 (Gruen et al 1979) at the different $60 ; \quad$ Zone $6 \quad$ follow-up times.

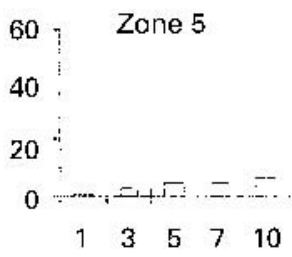

Years of follow-up the postoperative and the seven-year follow-up examinations in zones $1 \quad(\mathrm{p}<0.0001), 2(\mathrm{p}=0.002)$ and 7 $(\mathrm{p}<0.0001)$ (Wilcoxon matched-pair signed-rank test, Fig. 6). In all six regions which we evaluated (1 to 3,5 to 7 ) the bone area on the immediate postoperative radiograph was the most important variable for predicting changes in bone density up to seven years after the operation ( $\mathrm{p}=0.0005$ to 0.005 , stepwise linear regression). A large postoperative area of dense bone was associated with an increased loss of bone. Other factors such as stem length, age, weight, diagnosis, bone quality, stem length and occurrence of peroperative fracture had an inconsistent and usually small effect which varied according to the Gruen zone analysed.

Clinical and radiological survival. Analysis of failures of the cup (revision or migration) showed a ten-year survival rate of $46 \%( \pm 11)$ (Fig. 7). None of the variables which we considered in relation to the patient, the operation or the findings on the preoperative or immediate postoperative radiographs could predict this very high failure rate.

The survival rate for the stem was $81 \%( \pm 10)$ at the tenyear follow-up (Fig. 8). Stem failure was associated with a varus position of the stem on the early postoperative radiograph. The increase in relative risk per degree of varus 


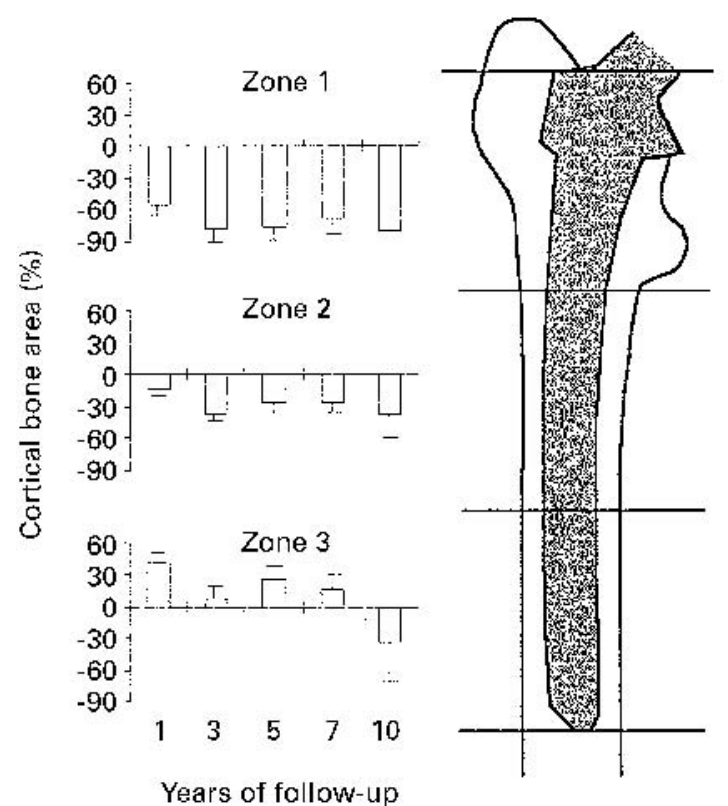

Years of follow-up

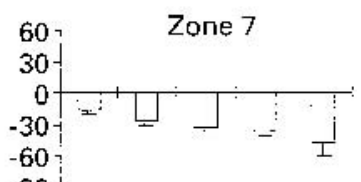

$-90^{-}$
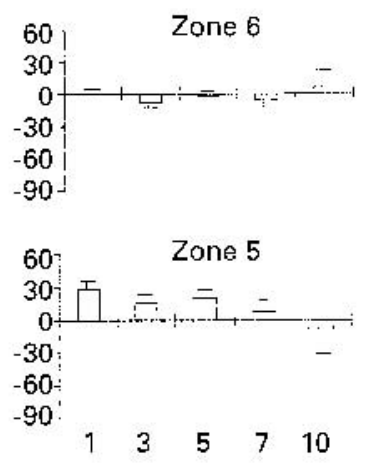

Years of follow-up ?
Fig. 6

The mean percentage $( \pm$ SEM) relative change in the cortical bone area surrounding the stem in zones 1 to 7 (Gruen et al 1979).

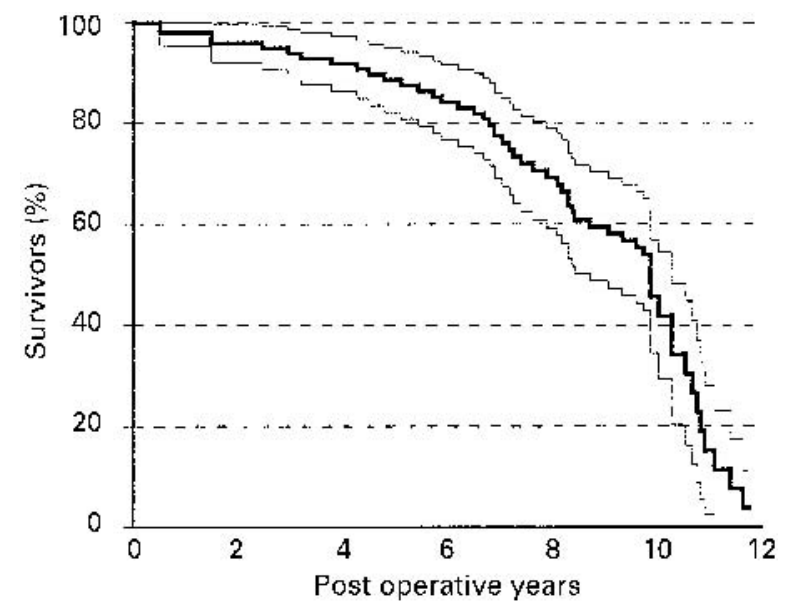

Fig. 7

Survival rate of the cup using revision or migration of more than $5 \mathrm{~mm}$ as the endpoint. The $95 \%$ confidence limits are shown.

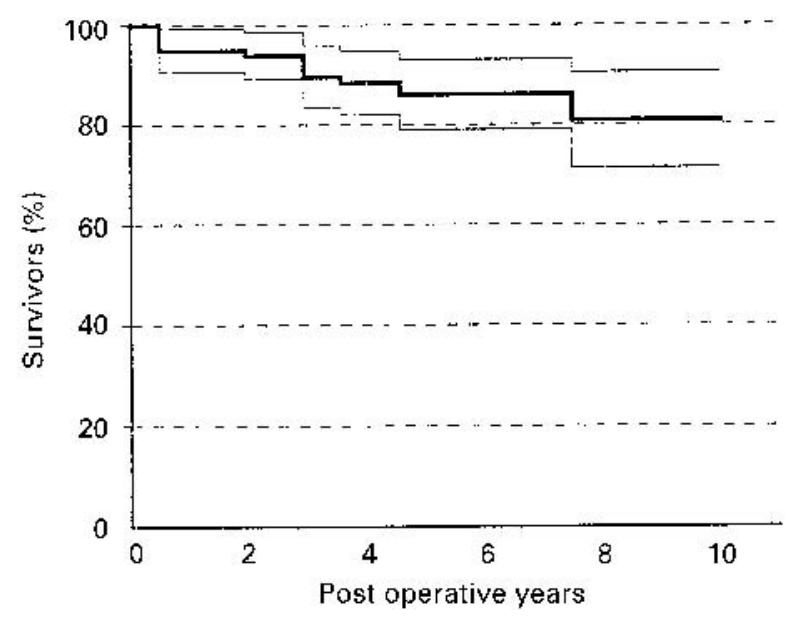

Fig. 8

Survival rate of the stem using revision or subsidence of more than $5 \mathrm{~mm}$ as the endpoint. The $95 \%$ confidence limits are shown. angulation was $3.5 \quad(1.5$ to $8.3, \mathrm{p}=0.003$, Cox regression).

\section{DISCUSSION}

The early to intermediate results for the first generation of threaded cups have already been reported (Engh, Griffin and Marx 1990; Lautiainen, Joukainen and Mäkelä 1994), but we are not aware of any reports of the long-term results. Sweetnam et al (1995) reported a high revision rate for threaded cups at six years, when used with a ribbed femoral prosthesis. Huiskes (1987) pointed out that stress concentration at the edge or tip of the threads imposes a focal overload on bone, which leads to bone necrosis and subsequent migration. In a radiostereometric study of 20 threaded cups, Snorrason and Kärrholm (1990) found a mean proximal migration of 0.6 to $0.7 \mathrm{~mm}$ in the first six postoperative months, which was more than three times higher than that observed for cemented cups and cementless pressfit cups (Snorrason 1990). They were concerned about the early and high migration rate and recommended that threaded cups should not be used until long-term clinical results were available. Other threaded cup designs coated with hydroxyapatite are now in use, but whether these new cups have better fixation and long-term performance is not yet known.

The Harris hip subscores for pain or limp did not deteriorate with time despite the high failure rate of the cup, possibly because cup migration does not always cause pain (Carlsson and Gentz 1984). When present, the pain or discomfort was different from that experienced before the operation. Moreover, before the symptoms became severe, 
Table VI. Assessment by the surgeon of the stem and cup stability, by percentage

\begin{tabular}{|c|c|c|c|c|c|c|c|}
\hline \multirow[b]{2}{*}{$\begin{array}{l}\text { Follow-up } \\
(\mathbf{y r})\end{array}$} & \multirow[b]{2}{*}{ Number } & \multicolumn{3}{|c|}{ Stem stability } & \multicolumn{3}{|c|}{ Cup stability } \\
\hline & & Stable & $\begin{array}{l}\text { Possibly } \\
\text { unstable }\end{array}$ & $\begin{array}{l}\text { Definitely } \\
\text { unstable }\end{array}$ & Stable & $\begin{array}{l}\text { Possibly } \\
\text { unstable }\end{array}$ & $\begin{array}{l}\text { Definitely } \\
\text { unstable }\end{array}$ \\
\hline 1 & 101 & 94 & 5 & 1 & 99 & 1 & \\
\hline 3 & 91 & 95 & 4 & 1 & 93 & 5 & 2 \\
\hline 5 & 87 & 98 & 2 & & 92 & 3 & 5 \\
\hline 7 & 63 & 96 & 4 & & 78 & 10 & 12 \\
\hline 10 & 43 & 98 & 2 & & 70 & 13 & 17 \\
\hline
\end{tabular}

Table VII. Number and percentage of implants showing subsidence exceeding $5 \mathrm{~mm}$ (stem) and vertical or horizontal migration (cup) exceeding $5 \mathrm{~mm}$. The number evaluated decreased mainly because of the comparatively high revision rate of the cup

\begin{tabular}{|c|c|c|c|c|}
\hline \multirow[b]{2}{*}{$\begin{array}{l}\text { Follow-up } \\
(\mathbf{y r})\end{array}$} & \multicolumn{2}{|l|}{ Stem } & \multicolumn{2}{|l|}{ Cup } \\
\hline & $\begin{array}{l}\text { Number } \\
\text { evaluated }\end{array}$ & Subsidence & $\begin{array}{l}\text { Number } \\
\text { evaluated }\end{array}$ & Migration \\
\hline 1 & 80 & 6 & 86 & 8 \\
\hline 3 & 73 & $10 \quad 14$ & 86 & $22 \quad 26$ \\
\hline 5 & 67 & $8 \quad 12$ & 77 & $26 \quad 34$ \\
\hline 7 & 66 & 69 & 70 & $32 \quad 46$ \\
\hline 10 & 32 & $5 \quad 16$ & 41 & $23 \quad 56$ \\
\hline
\end{tabular}

the cup was often revised because of the radiological findings. The comparatively long intervals between reviews and the tendency for the cup sometimes to fail rapidly when it penetrated the medial wall of the pelvis have contributed to inadequate documentation of cup failure in the scoring system. Furthermore, the high revision rate may have contributed to the selective survival of comparatively wellfixed cups and patients with a high threshold to pain. Once cup migration was diagnosed, it was usually progressive and resulted in clinical failure.

In contrast to the high and early migration rate of the threaded cup, the fully-porous-coated Lord stem was comparatively stable. Several reports (Engh, Bobyn and Glassman 1987; Engh and Bobyn 1988; Engh, Glassman and Suthers 1990; Engh et al 1992, 1994) have presented a high clinical success rate with this stem in both primary and revision cases. In our series subsidence greater than $5 \mathrm{~mm}$ was observed in 17 hips. Most of these patients were identified at the three-year follow-up or earlier, but so far these implants have not been revised. This suggests that subsidence of a fully porous-coated cobalt-chromium stem may result in a more durable fibrous fixation and is better tolerated by the patient (Engh et al 1992) than subsidence of a cemented stem (Kärrholm et al 1994a).

The next generation of uncemented stems had porous coating of only a short proximal area to minimise stressshielding. These designs are sometimes associated with early migration (Kärrholm et al 1994b) and have also a higher revision rate (Maric and Karpman 1992; Owen et al 1994).

Proximal stress protection due to distal fixation has been regarded as a major problem with fully-coated stems (Engh et al 1987, 1990, 1992, 1994; Huiskes et al 1987; Huiskes,
Weinans and Dalstra 1989; Huiskes 1990). Although there are no reports of the size of this problem in clinical series, these considerations have resulted in the rapid clinical use of the second generation of partially-coated stems.

Changed load distribution on the femoral bone surrounding the stem results in bone resorption in zones 1, 2 and 7 which, in our study, was particularly evident if a large proximal cortical bone area was recorded on the postoperative view; in cases with a small area there was almost no change. This agrees with previous findings (Engh et al 1992, 1994). In contrast to the finite-element models that predict a distal hypertrophy (Huiskes et al 1989; Skinner et al 1994), we did not find any increase in the cortical bone area in the distal Gruen zones at the seven-year follow-up. Skinner et al (1994) presented a finite-element analysis based on one retrieved AML stem of $15 \mathrm{~mm}$ diameter and suggested that a stress increase of $200 \%$ to $800 \%$ at the tip of a 5/8 coated prosthesis was responsible for distal cortical hypertrophy. They predict a near normal stress situation at the tip of a fully-coated stem. This is in agreement with our findings that the bone area in zones 3 and 5 did not change. We could not show any significant relationship between stem diameter and changes in the bone area. If present, this effect may have been masked by other variables which had the same but stronger influence. Insensitivity of our semiquantitative method and the lack of sequential bilateral measurements may also have had an effect. Future longterm studies using DEXA analysis may clarify this.

Conclusions. We cannot recommend the use of an uncoated threaded cup of the Lord design. The clinical impact of the bone remodelling observed after the insertion of a fullyporous coated stem is still unclear, but is a cause for concern, especially in relation to future revisions.

Financial support was obtained from Greta and Einar Askers Foundation, Neubergh Research Foundation and Göteborg Medical Association.

No benefits in any form have been received or will be received from a commercial party related directly or indirectly to the subject of this article.

\section{REFERENCES}

Carlsson AS, Gentz CF. Radiographic versus clinical loosening of the acetabular component in noninfected total hip arthroplasty. Clin Orthop 1984;185:145-50.

Charnley J. Low friction arthroplasty of the hip: theory and practice. Berlin, etc: Springer-Verlag, 1979:20-5.

DeLee JG, Charnley J. Radiological demarcation of cemented sockets in total hip replacement. Clin Orthop 1976;121:20-32. 
Engh CA, Bobyn JD, Glassman AH. Porous-coated hip replacement: the factors governing bone ingrowth, stress shielding and clinical results. J Bone Joint Surg [Br] 1987;69-B:45-55.

Engh CA, Bobyn JD. The influence of stem size and extent of porous coating on femoral bone resorption after primary cementless hip arthroplasty. Clin Orthop 1988;231:7-28.

Engh CA, Glassman AH, Suthers KE. The case for porous-coated hip implants: the femoral side. Clin Orthop 1990;261:63-81.

Engh CA, Griffin WL, Marx CL. Cementless acetabular components. J Bone Joint Surg [Br] 1990;72-B:53-9.

Engh CA, McGovern TF, Bobyn JD, Harris WH. A quantitative evaluation of periprosthetic bone-remodelling after cementless total hip arthroplasty. J Bone Joint Surg [Am] 1992;74-A:1009-20.

Engh CA, McGovern TF, Zettl-Schaffer KF, Ghafferpour M, Hooten JP. Evaluation of bone ingrowth into proximally and extensively porous coated AML prostheses retrieved at autopsy. Orthop Trans 1993-1994;17:940.

Gruen TA, McNeice GM, Amstutz HC. "Modes of failure" of cemented stem-type femoral components: a radiographic analysis of loosening. Clin Orthop 1979;141:17-27.

Hardinge K. The direct lateral approach to the hip. J Bone Joint Surg [Br] 1982;64-B:17-9.

Harris WH. Traumatic arthritis of the hip after dislocation and acetabular fractures: treatment by mold arthroplasty. J Bone Joint Surg [Am] 1969;51-A:737-55.

Huiskes R. Finite element analysis of acetabular reconstruction: noncemented threaded cups. Acta Orthop Scand 1987:58:620-5.

Huiskes R. The various stress patterns of press-fit, ingrown and cemented femoral stems. Clin Orthop 1990;261:27-38.

Huiskes R, Weinans H, Grootenboer HJ, et al. Adaptive bone-remodelling theory applied to prosthetic-design analysis. $J$ Biomech 1987; $20: 1135-50$.

Huiskes R, Weinans H, Dalstra M. Adaptive bone remodelling and biomechanical design considerations for non-cemented total hip arthroplasty. Orthopedics 1989;12:1255-67.

Kaplan EL, Meier P. Nonparametric estimation from incomplete observations. J Am Stat Assoc 1958;53:457-81.

Kärrholm J, Borssén B, Löwenhielm G, Snorrason F. Does early micromotions of femoral stem prostheses matter? 4-7-year stereoradiographic follow-up of 84 cemented hip prostheses. J Bone Joint Surg [Br] 1994a;76-B:912-7.
Kärrholm J, Malchau H, Snorrason F, Herberts P. Micromotion of femoral stems in total hip arthroplasty: a randomized study of cemented, hydroxyapatite-coated and porous-coated stems with roentgen stereophotogrammetric analysis. J Bone Joint Surg [Am] 1994b;76A: $1692-705$

Lautiainen IA, Joukainen J, Mäkelä EA. Clinical and roentgenographic results of cementless total hip arthroplasty. J Arthroplasty 1994;9:653-60.

Lord G. Total arthroplasty of the hip with cement for madreporic implants: experimental study of biologic anchorage and resistance of the implants, and clinical analysis of the first 300 cases. SICOT, XIV World Congress, Kyoto, Japan, 1978, 53.

Malchau H, Herberts P, Ahnfelt L. Prognosis of total hip replacement in Sweden: follow-up of 92675 operations performed 1978-1990. Acta Orthop Scand 1993;64:497-506.

Malchau H, Kärrholm J, Wang YX, Herberts P. Accuracy of migration analysis in hip arthroplasty: digitized and conventional radiography, compared to radiostereometry in 51 patients. Acta Orthop Scand 1995;66:418-24

Maric Z, Karpman RR. Early failure of noncemented porous coated anatomic total hip arthroplasty. Clin Orthop 1992;278:116-20.

Moore AT. Metal hip joint: a new self-locking vitallium prosthesis. South Med J 1952;45:1015-9.

Nunn D, Freeman MAR, Hill PF, Evans SJW. The measurement of migration of the acetabular component of hip prostheses. J Bone Joint Surg [Br] 1989;71-B:629-31.

Owen TD, Moran CG, Smith SR, Pinder IM. Results of uncemented porous-coated anatomic total hip replacement. J Bone Joint Surg [Br] 1994;76-B:258-62.

Skinner HB, Kim AS, Keyak JH, Mote CD. Femoral prosthesis implantation induces changes in bone stress that depend on the extent of porous coating. J Orthop Res 1994;12:553-63.

Snorrason F. Fixation of total hip arthroplasties: a clinical, radiographic and roentgen stereophotogrammetric analysis. Medical dissertation, University of Umeå 1990 .

Snorrason F, Kärrholm J. Primary migration of fully-threaded acetabular prostheses: a roentgen stereophotogrammetric analysis. $J$ Bone Joint Surg [Br] 1990;72-B:647-52.

Sweetnam DIS, Lavelle J, Muirhead Allwood W, Cohen B. Poor results of the ribbed hip system for cementless replacement. J Bone Joint Surg [Br] 1995;77-B:366-8. 